\title{
ARTICLE
}

Behaviour, Psychology and Sociology

\section{Long working hours and change in body weight: analysis of individual-participant data from 19 cohort studies}

\author{
Marianna Virtanen $\mathbb{1}^{1,2} \cdot$ Markus Jokela $^{3} \cdot$ Tea Lallukka ${ }^{4,5} \cdot$ Linda Magnusson Hanson ${ }^{2} \cdot$ Jaana Pentti $^{5,6,7}$. \\ Solja T. Nyberg ${ }^{5}$ - Lars Alfredsson ${ }^{8,9}$. G. David Batty ${ }^{10,11}$ - Annalisa Casini ${ }^{12}$. Els Clays $^{13}$ • Dirk DeBacquer ${ }^{13}$. \\ Jenni Ervasti $\oplus^{4,8}$. Eleonor Fransson ${ }^{2,8,14} \cdot$ Jaana I. Halonen ${ }^{2,4} \cdot$ Jenny Head $^{10} \cdot$ France Kittel $^{12} \cdot$ Anders Knutsson $^{15}$. \\ Constanze Leineweber ${ }^{2}$ - Maria Nordin ${ }^{16}$ - Tuula Oksanen $^{4}$ • Olli Pietiläinen ${ }^{5}$ - Ossi Rahkonen ${ }^{5}$ Paula Salo $^{4,17}$. \\ Archana Singh-Manoux ${ }^{10,18}$ - Sari Stenholm $\mathbb{1}^{6,7}$. Sakari B. Suominen ${ }^{6,19,20} \cdot$ Töres Theorell ${ }^{2}$ Jussi Vahtera $\mathbb{D}^{6,7}$. \\ Peter Westerholm ${ }^{21} \cdot$ Hugo Westerlund ${ }^{2} \cdot$ Mika Kivimäki $^{5,10}$
}

Received: 31 May 2019 / Revised: 1 October 2019 / Accepted: 27 October 2019 / Published online: 25 November 2019

(c) The Author(s) 2019. This article is published with open access

\begin{abstract}
Objective To examine the relation between long working hours and change in body mass index (BMI).

Methods We performed random effects meta-analyses using individual-participant data from 19 cohort studies from Europe, US and Australia $(n=122,078)$, with a mean of 4.4-year follow-up. Working hours were measured at baseline and categorised as part time ( $<35 \mathrm{~h} /$ week), standard weekly hours ( $35-40 \mathrm{~h}$, reference), $41-48 \mathrm{~h}, 49-54 \mathrm{~h}$ and $\geq 55 \mathrm{~h} /$ week (long working hours). There were four outcomes at follow-up: (1) overweight/obesity (BMI $\geq 25 \mathrm{~kg} / \mathrm{m}^{2}$ ) or (2) overweight (BMI $25-29.9 \mathrm{~kg} / \mathrm{m}^{2}$ ) among participants without overweight/obesity at baseline; (3) obesity (BMI $\geq 30 \mathrm{~kg} / \mathrm{m}^{2}$ ) among participants with overweight at baseline, and (4) weight loss among participants with obesity at baseline.

Results Of the 61,143 participants without overweight/obesity at baseline, 20.2\% had overweight/obesity at follow-up. Compared with standard weekly working hours, the age-, sex- and socioeconomic status-adjusted relative risk (RR) of overweight/obesity was 0.95 (95\% CI 0.90-1.00) for part-time work, 1.07 (1.02-1.12) for 41-48 weekly working hours, 1.09 (1.03-1.16) for $49-54 \mathrm{~h}$ and $1.17(1.08-1.27)$ for long working hours $(P$ for trend $<0.0001)$. The findings were similar after multivariable adjustment and in subgroup analyses. Long working hours were associated with an excess risk of shift from normal weight to overweight rather than from overweight to obesity. Long working hours were not associated with weight loss among participants with obesity.

Conclusions This analysis of large individual-participant data suggests a small excess risk of overweight among the healthyweight people who work long hours.
\end{abstract}

\section{Introduction}

Obesity is a modifiable risk factor for an array of health problems, including cardiovascular disease, type 2 diabetes, certain cancers and dementia that collectively contribute to a substantial proportion of disease burden and death worldwide $[1,2]$. Resulting also from changes in living and

Supplementary information The online version of this article (https:// doi.org/10.1038/s41366-019-0480-3) contains supplementary material, which is available to authorised users.

Marianna Virtanen

marianna.virtanen@uef.fi

Extended author information available on the last page of the article working environments, the global 'epidemic' of obesity currently affects all age groups, all populations, and countries of all income levels [3, 4].

Psychosocial work environment may have a role in weight control although little research has been published beyond perceived stress at work. Current evidence suggests a modest association between work stress and overweight or obesity, with limited support from longitudinal studies $[5,6]$. Another work-related aspect, long working hours, may also contribute to weight gain, owing to extended periods of sitting, reduced opportunities for exercise, changes in eating habits leading to positive energy balance, and subsequently to weight gain.

Previous studies suggest associations of long working hours with increased incidence of cardiovascular disease 
and type 2 diabetes [7-9], for which obesity is also a major risk factor $[10,11]$. There are few prospective studies examining the link between long working hours and changes in body weight, and the findings are inconsistent with positive [12-15], and null [16] associations reported. Further, one study found that long working hours may confer protection against gaining weight [17]. In addition to the paucity of evidence, studies in this field are typically insufficiently powered to examine weight gain amongst people who are previously not overweight.

Accordingly, with a large collaborative study of 19 cohorts from Europe, the US and Australia, we examined the association between working hours and subsequent change in body mass index (BMI), including an analysis of long working hours in relation to each stage of weight gain: from non-overweight to overweight or obesity, from overweight to obesity. Long working hours may also be associated with lower probability of weight loss among those with obesity. For the first time to our knowledge, the size of this dataset allows to examine also this issue.

\section{Materials and methods}

\section{Participants}

We used data from 19 cohort studies (Supplementary Table 1) which were either taken from IndividualParticipant-Data Meta-analysis in Working Populations (IPD-Work) Consortium [18], or were available from one of two digital repositories of research data (the InterUniversity Consortium for Political and Social Research; http://www.icpsr.umich.edu/icpsrweb/ICPSR/) or the UK Data Service (http://ukdataservice.ac.uk/). The studies were chosen according to the availability of working hours and BMI data in a prospective cohort design with the follow-up not exceeding 10 years. All studies have their own approval from their relevant local or national ethics committee, and all participants had given informed consent.

Six cohort studies were from the UK: British Birth Cohort 1970 (BCS1970) [19], British Household Panel Survey [20], National Child Development Study [21], Whitehall II study [22], UK Household Longitudinal Study [23], and English Longitudinal Study of Aging [24]; four were from the US: Americans' Changing Lives [25], Midlife in the United States [26], Health and Retirement Study [27], and National Longitudinal Survey of Youth [28]; three from Finland: Finnish Public Sector Study [29], Health and Social Support Study [30], and Helsinki Health Study (HHS) [31]; two from Sweden: Swedish Longitudinal Occupational Survey of Health [32] and Work, Lipids and Fibrinogen Norrland [33]; and one each from Belgium: Belgian Job Stress Project (Belstress) [34];
Germany: German Socioeconomic Panel Survey [35]; and Australia: Household, Income, and Labour Dynamics in Australia [36]. In addition, we included the Survey of Health, Ageing and Retirement in Europe [37], which included data from multiple European countries (France, Germany, Finland, Sweden, Denmark, Slovenia, Cyprus, Romania, Bulgaria, Greece, Czech Republic, Slovakia, Hungary, Estonia, Latvia, Lithuania, Poland, The Netherlands, Belgium, Luxembourg, Spain, Portugal, Italy, Switzerland, and Austria).

In total, there were 122,078 participants for prospective analyses who were at work and provided data on working hours, sociodemographic characteristics and repeat measurements of BMI.

\section{Assessment of working hours}

In all cohorts, information on working hours at baseline was obtained from self-report. We used the previously used categorisation of weekly working hours: $<35$ (part time), 35-40 (reference group), 41-48, 49-54 and $\geq 55 \mathrm{~h}$ (long working hours) [38, 39]. In all these studies, working hours data were based on a continuous response, the only exception being HHS [31] where responses were based on a pre-defined categorises $(<30,30-40,41-50$ and $>50 \mathrm{~h} /$ week). For the purposes of the present analyses, we treated in that study the category of $30-40 \mathrm{~h} /$ week as the reference with $<30 \mathrm{~h} /$ week corresponding to part time, $41-50 \mathrm{~h} /$ week corresponding to the $41-48 \mathrm{~h}$ category in meta-analysis and $>50$ working hours corresponding to the $\geq 55 \mathrm{~h}$ category.

\section{Assessment of body mass index (BMI)}

At baseline and follow-up, BMI (expressed as $\mathrm{kg} / \mathrm{m}^{2}$ ) was based on self-reported height and weight in all cohort studies except Whitehall II and Belstress, in which height and weight were measured directly during a standardised clinical examination. The following categories at baseline and at follow-up were calculated: not overweight $(\mathrm{BMI}<25.0)$; overweight (25.0-29.9); obese (30.0 or more). For those with obesity, we also determined whether they lost weight to non-obesity or had weight loss of $>5 \%$ [40] between the baseline and follow-up.

\section{Covariates}

All covariates were measured at the baseline and were typically either self-reported or register-based depending on the study in question. Socioeconomic status was based on occupational position, or educational qualification and was categorised as high, intermediate, and low. Health-related factors included pre-existing chronic somatic disease (e.g., 
cardiovascular disease, diabetes, asthma, rheumatoid arthritis), and psychological distress or depressive symptoms. Smoking (current vs non-smoker) [41] and leisuretime physical activity (low vs intermediate/high) [42] were both self-reported.

\section{Statistical analyses}

We used a two-stage approach to the present meta-analysis [43]. First, we estimated study-specific associations with individual participant data. With the outcomes of interest being relatively common, we used log-binomial regression analysis with relative risk (RR) as an estimator of effect and its $95 \%$ confidence intervals as an indicator of precision.

In the second stage, we used random effects metaanalysis to obtain a pooled estimate from the first-stage study-specific estimates. We conducted our analyses in seven parts. Part 1: forest plots including cohort-specific estimates from main analysis comparing different working hours categories in relation to weight gain - that is, transition from non-overweight to overweight/obesity), adjusted for age, sex and socioeconomic status. Significance of trend was assessed by meta-regression.

Further parts were conducted comparing $\geq 55$ weekly working hours to 35-40 h. Part 2: weight gain outcome as in analysis 1 plus adjustment for chronic somatic disease, psychological distress/depressive symptoms, smoking and physical activity. Part 3: sensitivity analysis excluding smokers (adjusted for age, sex and socioeconomic status). Part 4: sensitivity analysis excluding those with chronic disease at baseline (adjusted for age, sex and socioeconomic status). Part 5: sensitivity analysis excluding those with underweight $(\mathrm{BMI}<18.5, n=1343$; adjusted for age, sex and socioeconomic status). Part 6: subgroup analyses by sex, age groups ( $<50$ years and $\geq 50$ years), socioeconomic status group, and by follow-up time (1-2, 3-4 and 5-9 years).

Part 7: further transitions between BMI categories from baseline to follow-up: from non-overweight to overweight only; from overweight to obesity; and weight loss from obesity to non-obesity; and from obesity to $>5 \%$ weight loss.

Heterogeneity of the study-specific estimates was assessed using the $I^{2}$ statistic and $\tau$ [44] with a higher numerical value denoting greater heterogeneity. We calculated population attributable fraction (PAF) [18, 45] for overtime (>40) weekly hours, which indicates how much (in percentage) overweight/obesity in the general population would be reduced if all full-time workers worked standard $35-40 \mathrm{~h}$, assuming that the associations are causal. The study-specific results were computed using SAS 9.4 (Cary, NC) and the meta-analyses were conducted using Stata 15 (College Station, TX).

\section{Results}

Of the 122,078 participants, $61,143(50.1 \%)$ were without overweight or obesity at baseline; 42,965 (35.2\%) had overweight and 17,970 (14.7\%) had obesity. Of those without overweight/obesity, 31,703 (51.9\%) worked standard $35-40 \mathrm{~h}$ a week, $10,568(17.3 \%)$ worked $41-48 \mathrm{~h}$, $3897(6.4 \%)$ worked 49-54 h and 3947 (6.5\%) worked $55 \mathrm{~h}$ or more. The number of part-time workers was 11,028 $(18.0 \%)$. Of the cohort, $12,349(20.2 \%)$ gained weight and were overweight or obese at follow-up. The duration of follow-up across studies was 1-9 years (mean 4.4 years), corresponding to 267,491 person-years at risk for the participants without overweight/obesity (Supplementary Table 1).

Figure 1a-d shows the forest plots of RRs for new-onset overweight/obesity at follow-up by the working hour categories. Compared with working standard 35-40 h a week, working 41-48 h was associated with $\mathrm{RR}=1.07(95 \% \mathrm{CI}$ 1.02-1.12; Panel a); working 49-54 h with $\mathrm{RR}=1.09(95 \%$ CI 1.03-1.16; Panel b) and working $55 \mathrm{~h}$ or more with $\mathrm{RR}=1.17$ (95\% CI 1.08-1.27; Panel c). Part-time work, in turn, was associated with $\mathrm{RR}=0.95$ (95\% CI 0.90-1.00; Panel d). These findings suggest a dose-response relation between longer working hours and the risk of increasing body weight ( $P$ for trend $<0.0001$ in meta-regression; a graph presented in Fig. 2). Heterogeneity, as estimated by $I^{2}$, suggested no (a, b, and d) or moderate (c) heterogeneity between study-specific estimates. $\tau$-values in Panels a-d were $0,0,0.10$ and 0.03 , respectively.

Multivariable adjustment for chronic somatic disease, mental health and lifestyle attenuated the association between long working hours and onset of overweight/obesity, from 1.17 (95\% CI 1.08-1.27) to $1.12(95 \% \mathrm{CI}$ 1.01-1.25) (Fig. 3). Sensitivity analyses in which we excluded cigarette smokers, those with chronic somatic diseases, and those with underweight, had little impact on the associations. Similarly, results were unchanged following subgroup analyses in which we stratified the data by sex, age, socioeconomic group, or duration of follow-up. The greatest heterogeneity in effect estimates was evident in men, among those with high or low socioeconomic status, and in studies with medium-length follow-up (3-4 years). The overall PAF for overtime $(>40 \mathrm{~h})$ work was $2.8 \%$, suggesting that if all full-time workers worked standard $35-40 \mathrm{~h}$, the population level reduction of overweight/ obesity would be $2.8 \%$.

Figure 4 shows the results of further analysis of the development of BMI between baseline and follow-up. Long $(\geq 55)$ weekly working hours were associated with weight gain from non-overweight to overweight $(\mathrm{RR}=1.16,95 \%$ CI 1.07-1.26 and no significant heterogeneity), but not from overweight to obesity ( $\mathrm{RR}=1.01,95 \%$ CI $0.89-1.14)$. No 

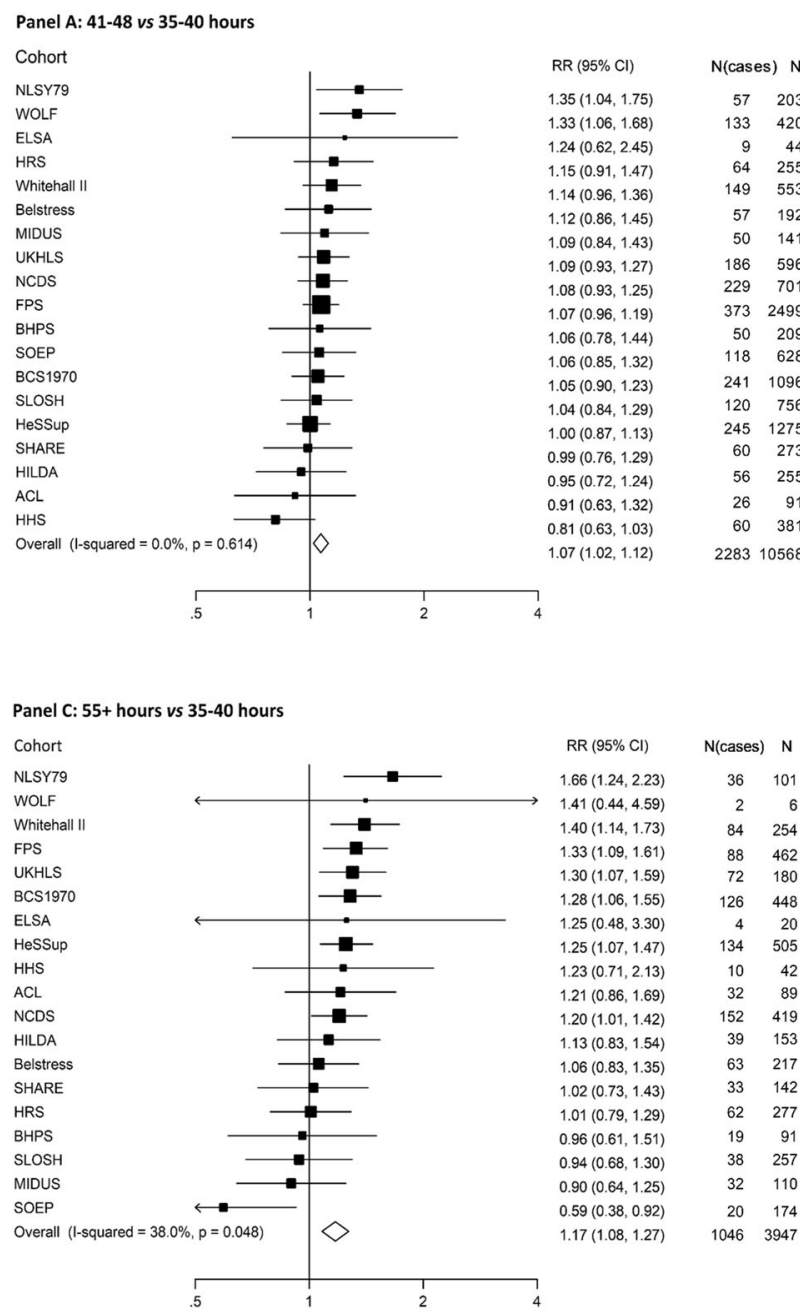

Fig. 1 Relative risk (RR) and 95\% confidence interval for the association between working hour category at baseline and onset of overweight/obesity at follow-up in participants with BMI $<25 \mathrm{~kg} / \mathrm{m}^{2}$ at

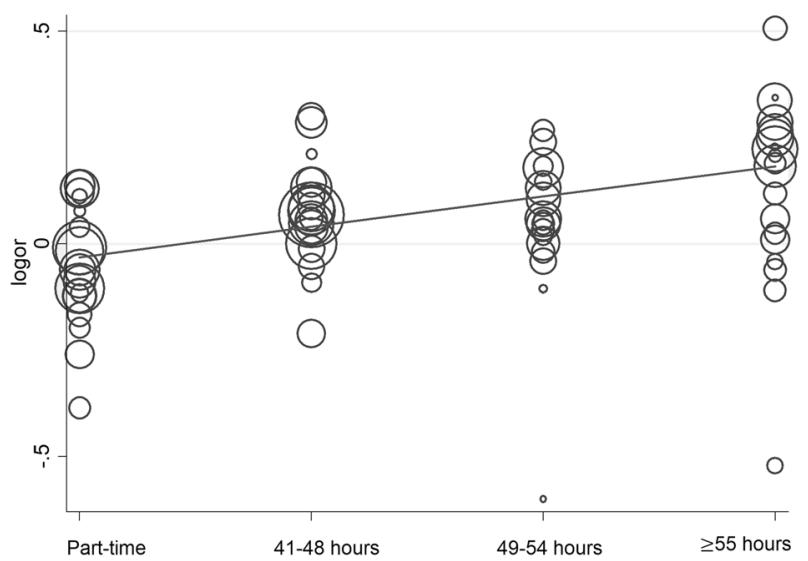

Fig. 2 Illustration of a dose-response pattern (trend) on the association between working hours and onset of overweight/obesity from a metaanalysis of 19 studies
Panel B: $49-54$ hours vs $35-40$ hours

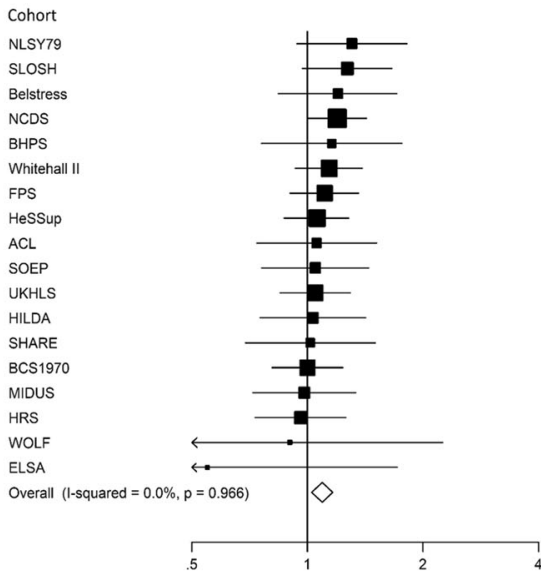

\begin{tabular}{crr} 
RR $(95 \%$ Cl) & N(cases) & \multicolumn{1}{c}{$\mathrm{N}$} \\
$1.31(0.94,1.82)$ & 31 & 115 \\
$1.27(0.97,1.66)$ & 56 & 290 \\
$1.20(0.84,1.71)$ & 25 & 78 \\
$1.20(1.00,1.42)$ & 128 & 355 \\
$1.16(0.76,1.76)$ & 21 & 81 \\
$1.14(0.93,1.39)$ & 99 & 370 \\
$1.11(0.90,1.36)$ & 83 & 534 \\
$1.06(0.87,1.28)$ & 92 & 431 \\
$1.06(0.74,1.51)$ & 26 & 78 \\
$1.05(0.76,1.44)$ & 40 & 218 \\
$1.05(0.85,1.29)$ & 74 & 234 \\
$1.03(0.75,1.42)$ & 38 & 163 \\
$1.02(0.69,1.50)$ & 23 & 102 \\
$1.00(0.81,1.24)$ & 95 & 434 \\
$0.98(0.72,1.34)$ & 35 & 111 \\
$0.96(0.73,1.26)$ & 52 & 249 \\
$0.90(0.36,2.25)$ & 4 & 21 \\
$0.55(0.18,1.71)$ & 3 & 33 \\
$1.09(1.03,1.16)$ & 925 & 3897
\end{tabular}

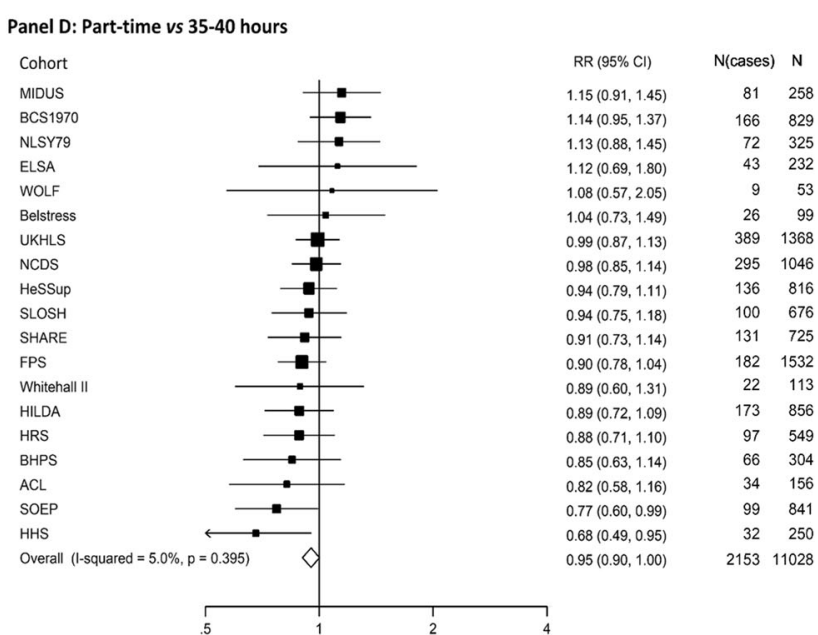

baseline (random effects meta-analysis adjusted for age, sex and socioeconomic status) (a-d)

associations were observed between working hours and weight loss among participants with obesity.

\section{Discussion}

In this individual-participant data meta-analysis of 19 cohort studies with 122,078 participants, we examined the prospective associations between working hours and weight change in a greater detail than has previously been possible. We found a modest association but a suggestive doseresponse relation between longer working hours at baseline and the risk of weight gain from non-overweight to overweight or obesity at follow-up. The association with weekly working hours of 55 or more was further examined and the analyses suggest that the finding is robust to adjustments and replicable across subgroups. However, our detailed 
Fig. 3 Summary relative risk (RR) of the onset of overweight/ obesity for long ( $\geq 55 \mathrm{~h} /$ week) working hours at baseline compared with $35-40 \mathrm{~h}$ from serial adjustments and subgroup analyses in participants with BMI $<25 \mathrm{~kg} / \mathrm{m}^{2}$ at baseline. Relative risk ratios are adjusted for age, sex and socioeconomic status as appropriate

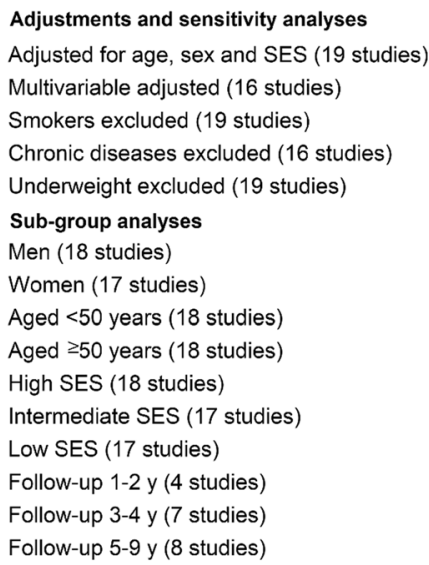

Adjustments and sensitivity analyses Adjusted for age, sex and SES (19 studies) Multivariable adjusted (16 studies) Smokers excluded (19 studies) Chronic diseases excluded (16 studies) Underweight excluded (19 studies) Sub-group analyses Men (18 studies) Women (17 studies) Aged $<50$ years ( 18 studies) Aged $\geq 50$ years ( 18 studies) High SES (18 studies) Intermediate SES (17 studies) Low SES (17 studies)

Follow-up 1-2 y (4 studies) Follow-up 3-4 y (7 studies) Follow-up 5-9 y (8 studies)

\begin{tabular}{crll}
$R R(95 \% \mathrm{Cl})$ & $I^{2} \%$ & $(\mathrm{p})$ & \multicolumn{1}{l}{$\tau$} \\
$1.17(1.08,1.27)$ & 38.0 & $(0.048)$ & 0.10 \\
$1.12(1.01,1.25)$ & 45.4 & $(0.025)$ & 0.14 \\
$1.15(1.03,1.27)$ & 44.8 & $(0.019)$ & 0.15 \\
$1.13(1.01,1.27)$ & 40.7 & $(0.046)$ & 0.14 \\
$1.15(1.08,1.24)$ & 25.4 & $(0.151)$ & 0.07 \\
& & & \\
$1.24(1.09,1.41)$ & 56.4 & $(0.002)$ & 0.19 \\
$1.08(0.97,1.20)$ & 0.0 & $(0.570)$ & 0.00 \\
$1.19(1.07,1.33)$ & 44.8 & $(0.021)$ & 0.14 \\
$1.15(1.05,1.26)$ & 32.5 & $(0.091)$ & 0.11 \\
$1.15(1.00,1.32)$ & 48.2 & $(0.012)$ & 0.19 \\
$1.20(1.07,1.35)$ & 0.0 & $(0.542)$ & 0.00 \\
$1.28(1.07,1.52)$ & 46.0 & $(0.020)$ & 0.23 \\
$1.09(0.92,1.29)$ & 32.1 & $(0.220)$ & 0.10 \\
$1.21(1.00,1.45)$ & 61.0 & $(0.017)$ & 0.19 \\
$1.19(1.09,1.30)$ & 3.3 & $(0.404)$ & 0.02 \\
& & & \\
& & &
\end{tabular}
RR Heterogeneity $(95 \% \mathrm{Cl}) \quad 1^{2} \% \quad(p) \quad \tau$ 1 (ref) $1.16(1.07,1.26) 31.2(0.096) 0.09$ 1 (ref) $1.01(0.89,1.14) 58.4(0.001) 0.20$ (18 studies) From obesity to non-obesity 35-40 (standard) (13 studies)

From obesity to $>5 \%$ weight loss (18 studies)

\section{per week}

35-40 (standard) $>55$ (long hours) $\geq 55$ (long hours) $>55$ (long hours) 35-40 (standard) $\geq 55$ (long hours) 35-40 (standard)

\subsection{0}

14 0.15 14 07 19 00 0.14 0.11 0.19 .00 23 10 19 02 Fig. 4 Summary relative risk of
weight changes from baseline to working hours at baseline
work compared with 35-40 working hours per week
Weight loss

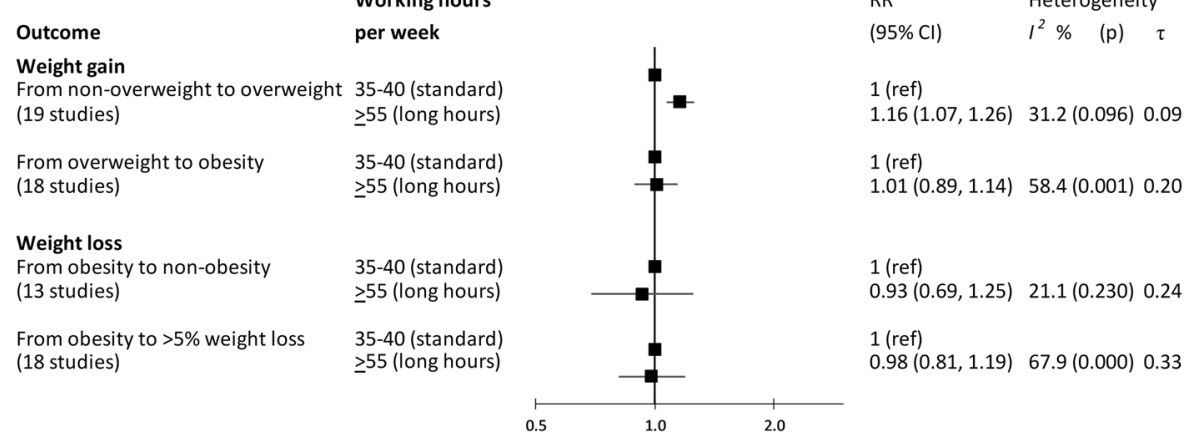

analysis of the development of BMI showed that long working hours may increase the risk of a shift from normal to overweight but not from overweight to the obese category. Working hours were not associated with weight loss among those who had obesity.

Our results are in line with previous prospective studies suggesting a positive association between long working hours and BMI [12-15] but in contrast with one small-scale Japanese study which reported that long working hours were associated with lower likelihood of weight gain [17]. The previous studies with positive findings were limited to datasets that included older [12] or younger [13] men and women, middle-aged women only [14], or industrial employees [15]. With a large dataset we were able to obtain more precise estimates for the association between working hours and BMI, including separate analyses for men and women and across age groups and socioeconomic strata.

The longest $(\geq 55)$ weekly working hour category was associated with a 1.17-fold risk of new-onset overweight or obesity in the model adjusted for age, sex and socioeconomic status. The estimates from other working hour categories suggested a dose-response relationship although the overall association was modest. The association remained after adjustment for other lifestyle factors, chronic diseases and psychological distress, exclusion of smokers and those with chronic somatic disease or underweight, and in subgroup analyses by sex, age, socioeconomic status and length of follow-up. Thus, although weak, the association between long working hours and weight gain appeared to be robust. Our sensitivity analyses suggested that we can be most confident with the finding regarding a shift from normal to overweight category, with a RR of 1.16 with no significant heterogeneity in study-specific estimates.

Possible mechanism explaining the association between long working hours and weight gain may be extended periods of sitting, because today, many occupations are sedentary. Other mechanisms may be linked to too little exercise and unhealthy diet, because people with long working hours may not have resources, time or energy to engage in a healthy lifestyle [7]. Part-time workerspotentially having more time-seemed to have a lower risk of weight gain in our meta-analysis. This finding is in line with previous observations on Australian women who worked part time and had a smaller risk of weight gain than women who worked full time [14]. In our study, the 1.17fold risk with long ( 255 ) weekly working hours attenuated to 1.12 in a multivariable adjusted model adding physical and mental health, smoking and physical inactivity. 
However, information on eating habits, one of the potential underlying mechanisms, was not available in our study. Another unmeasured mechanism could be prolonged sitting time at work, because our measures of physical activity covered only leisure-time physical inactivity. However, even though prolonged overall sitting time has been associated with a higher occupational status [46], our findings did not suggest differences the association between long working hours and weight gain between socioeconomic groups. Moreover, commuting hours would be an important factor to be considered in further studies to increase our understanding of the relationship between time-related factors and weight gain. However, previous studies have suggested that unhealthy lifestyle is not a major mechanism between long working hours and cardiovascular diseases [7]. The modest association found between long working hours and weight gain in the present study also supports the hypothesis of mechanisms being other than obesity.

Long working hours were not associated with weight loss among participants with obesity. However, we could not distinguish between intentional and unintentional weight loss. One could assume that psychosocial factors, such as work-related stress, affect success in intentional attempts to lose weight among overweight individuals whereas other factors, such as the onset of physical diseases may contribute to unintentional weight loss. However, the relationship between stress and weight change has been suggested to be complex as for some people stress seem to induce weight gain whereas for others it is associated with weight loss and for still others stress has no significant effect on weight [6].

Important strengths of our study include the first largescale longitudinal individual participant data analysis of the association between working hours and weight change. A large sample size with harmonised variables reduces the likelihood of random error. We included cohort data from several countries in Europe, US and Australia, which increases generalisability of our findings, however, to those countries only. Notable limitations include an observational study design, which does not allow us to determine causality, and self-reported exposure to working hours and BMI in almost all cohorts. Working hours was measured only once although for some employees, long reported working hours may have had been a temporary 'peak' which was resolved shortly after the baseline survey whereas for others, excessive hours may have had been persistent. Selfreport may also involve recall bias if the participants' recall hours worked inaccurately or if they overestimate their height and underestimate their weight [47]. However, the validity of self-reported working hours has been found to be at least moderate [48] and the associations between BMI and cardiometabolic disease have been shown to be similar for self-reported and directly measured weight and height
[49]. We were thus unable to assess whether the relatively small overall risk was an underestimate due to misclassification of the exposure or outcome. However, exposure misclassification may contribute to both under- and over-estimation of associations.

The PAF was $2.8 \%$ which suggests that overweight/ obesity could be reduced by $2.8 \%$ if all full-time workers worked standard 35 to $40 \mathrm{~h}$ a week and the observed associations were causal. Given the multifactorial aetiology of obesity, this PAF is not trivial for population-wide prevention although the clinical significance at the individual level is modest. This size of PAF is comparable with those obtained for the relation of work stress (3.4\%) [18] and depressive symptoms (1.1\%) [45] with coronary heart disease although direct comparisons with BMI are not available. However, due to the causality assumption, findings on PAF in observational studies should be interpreted cautiously.

In conclusion, this individual participant meta-analysis of 19 cohort studies found a small excess risk of overweight among individuals who work longer hours. Detailed analyses were consistent with the hypothesis that the impact of long working hours involves the progression from normal to overweight rather than from overweight to obesity and that working long hours is not associated with weight loss among individuals with obesity. Future longitudinal studies assessing causality and underlying mechanisms, such as diet and accelerometer-measured physical activity would increase our understanding of the effects of long working hours on changes in body weight.

Funding Era-Age2 grant, Academy of Finland (264944, 287488 and 319200), UK Medical Research Council (R024227/1), NordForsk (the Research Programme for Health and Welfare), Academy of Finland (311492), Helsinki Institute of Life Science.

\section{Compliance with ethical standards}

Conflict of interest The authors declare that they have no conflict of interest.

Publisher's note Springer Nature remains neutral with regard to jurisdictional claims in published maps and institutional affiliations.

Open Access This article is licensed under a Creative Commons Attribution 4.0 International License, which permits use, sharing, adaptation, distribution and reproduction in any medium or format, as long as you give appropriate credit to the original author(s) and the source, provide a link to the Creative Commons license, and indicate if changes were made. The images or other third party material in this article are included in the article's Creative Commons license, unless indicated otherwise in a credit line to the material. If material is not included in the article's Creative Commons license and your intended use is not permitted by statutory regulation or exceeds the permitted use, you will need to obtain permission directly from the copyright holder. To view a copy of this license, visit http://creativecommons. org/licenses/by/4.0/. 


\section{References}

1. GBD 2016 Causes of Death Collaborators. Global, regional, and national age-sex specific mortality for 264 causes of death, 19802016: a systematic analysis for the Global Burden of Disease Study 2016. Lancet. 2017;390:1151-210.

2. Bray GA, Kim KK, Wilding JPH, World Obesity Forum. Obesity: a chronic relapsing progressive disease process. A position statement of the World Obesity Federation. Obes Rev. 2017;18:715-23.

3. Guariguata L, Whiting DR, Hambleton I, Beagley J, Linnenkamp U, Shaw JE. Global estimates of diabetes prevalence for 2013 and projections for 2035. Diabetes Res Clin Pract. 2014;103:137-49.

4. Malik VS, Willett WC, Hu FB. Global obesity: trends, risk factors and policy implications. Nat Rev Endocrinol. 2013;9:13-27.

5. Solovieva S, Lallukka T, Virtanen M, Viikari-Juntura E. Psychosocial factors at work, long work hours, and obesity: a systematic review. Scand J Work Environ Health. 2013;39:241-58.

6. Kivimaki M, Singh-Manoux A, Nyberg S, Jokela M, Virtanen M. Job strain and risk of obesity: systematic review and meta-analysis of cohort studies. Int J Obes. 2015;39:1597-1600.

7. Virtanen M, Kivimaki M. Long working hours and risk of cardiovascular disease. Curr Cardiol Rep. 2018;20:123.

8. Kivimaki M, Virtanen M, Kawachi I, Nyberg S, Alfredsson L, Batty GD, et al. Long working hours, socioeconomic status, and the risk of incident type 2 diabetes: a meta-analysis of published and unpublished data from 222120 individuals. Lancet Diabetes Endocrinol. 2015;3:27-34.

9. Kivimaki M, Nyberg ST, Batty GD, Kawachi I, Jokela M, Alfredsson L, et al. Long working hours as a risk factor for atrial fibrillation: a multi-cohort study. Eur Heart J. 2017;38:2621-8.

10. American Diabetes Association. Standards of medical care in diabetes. Diabetes Care. 2015;38:S1-S94.

11. Piepoli MF, Hoes AW, Agewall S, Albus C, Brotons C, Catapano AL, et al. 2016 European guidelines on cardiovascular disease prevention in clinical practice: the Sixth Joint Task Force of the European Society of Cardiology and other societies on cardiovascular disease prevention in clinical practice (constituted by representatives of 10 societies and by invited experts), developed with the special contribution of the European Association for Cardiovascular Prevention \& Rehabilitation (EACPR). Eur Heart J. 2016;37:2315-81.

12. Mercan MA. A research note on the relationship between long working hours and weight gain for older workers in the United States. Res Aging. 2014;36:557-67.

13. Courtemanche C. Longer hours, longer waistlines? The relationship between work hours and obesity. Forum Health. Econ Policy. 2009;12:1-33.

14. Au N, Hauck K, Hollingsworth B. Employment, work hours and weight gain among middle-aged women. Int $\mathrm{J}$ Obes. 2013;37:718-24.

15. Lallukka T, Sarlio-Lahteenkorva S, Kaila-Kangas L, Pitkaniemi J, Luukkonen R, Leino-Arjas P. Working conditions and weight gain: a 28-year follow-up study of industrial employees. Eur $\mathbf{J}$ Epidemiol. 2008;23:303-10.

16. Roos E, Lallukka T, Rahkonen O, Lahelma E, Laaksonen M. Working conditions and major weight gain-a prospective cohort study. Arch Environ Occup Health. 2013;68:166-72.

17. Wada K, Katoh N, Aratake Y, Furukawa Y, Hayashi T, Satoh E, et al. Effects of overtime work on blood pressure and body mass index in Japanese male workers. Occup Med. 2006;56:578-80.

18. Kivimaki M, Nyberg ST, Batty GD, Fransson E, Heikkilä K, Alfredsson L, et al. Job strain as a risk factor for coronary heart disease: a collaborative meta-analysis of individual participant data. Lancet. 2012;380:1491-7.

19. Elliott J, Shepherd P. Cohort profile: 1970 British Birth Cohort (BCS70). Int J Epidemiol. 2006;35:836-43.
20. Taylor MF, Brice J, Buck N, Prentice-Lane E. British household panel survey - user manual-volume A: Introduction, technical report and appendices. Colchester, England: University of Essex; 2010.

21. Power C, Elliott J. Cohort profile: 1958 British birth cohort (National Child Development Study). Int J Epidemiol. 2006;35:34-41.

22. Marmot M, Brunner E. Cohort Profile: the Whitehall II study. Int J Epidemiol. 2005;34:251-6.

23. Burton J, Laurie H, Lynn P. Understanding society desgin overview. Understanding society: early findings from the first wave of the UK's household longitudinal study. Essex: Institute for Social and Economic Research, University of Essex; 2011. p. 129-40.

24. Steptoe A, Breeze E, Banks J, Nazroo J. Cohort profile: the English longitudinal study of ageing. Int J Epidemiol. 2013;42:1640-8.

25. House JS, Lantz PM, Herd P. Continuity and change in the social stratification of aging and health over the life course: evidence from a nationally representative longitudinal study from 1986 to 2001/2002 (Americans' Changing Lives Study). J Gerontol B Psychol Sci Soc Sci. 2005;60 Spec No 2:15-26.

26. Brim OG, Baltes PB, Bumpass LL, Cleary PD, Featherman DL, Hazzard WR, et al. Midlife in the United States (MIDUS 1), 1995-1996. Ann Arbor, MI: Inter-university Consortium for Political and Social Research; 2018. https://www.icpsr.umich.edu/ icpsrweb/NACDA/studies/2760.

27. Heeringa SG, Connor JH. Technical description of the health and retirement survey sample design. University of Michigan: Ann Arbor, MI. 1995 http://hrsonline.isr.umich.edu.

28. Bureau of Labor Statistics. NLSY79. In: National Longitudinal Surveys, NLS Handbook 2005. United States Department of Labor: 2005. https://www.bls.gov/nls/handbook/nlshndbk.htm.

29. Kivimaki M, Lawlor DA, Davey Smith G, Kouvonen A, Virtanen $\mathrm{M}$, et al. Socioeconomic position, co-occurrence of behaviorrelated risk factors, and coronary heart disease: the Finnish Public Sector study. Am J Public Health. 2007;97:874-9.

30. Korkeila K, Suominen S, Ahvenainen J, Ojanlatva A, Rautava P, et al. Non-response and related factors in a nation-wide health survey. Eur J Epidemiol. 2001;17:991-9.

31. Lahelma E, Aittomaki A, Laaksonen M, Lallukka T, Martikainen P, Piha K, et al. Cohort profile: the Helsinki Health Study. Int J Epidemiol. 2013;42:722-30.

32. Magnusson Hanson LL, Leineweber C, Persson V, Hyde M, Theorell T, Westerlund H. Cohort Profile: the Swedish Longitudinal Occupational Survey of Health (SLOSH). Int J Epidemiol. 2018;47:691-2i.

33. Alfredsson L, Hammar N, Fransson E, de Faire U, Hallqvist J, Knutsson A, et al. Job strain and major risk factors for coronary heart disease among employed males and females in a Swedish study on work, lipids and fibrinogen. Scand J Work Environ Health. 2002;28:238-48.

34. De Bacquer D, Pelfrene E, Clays E, Mak R, Moreau M, de Smet $\mathrm{P}$, et al. Perceived job stress and incidence of coronary events: 3year follow-up of the Belgian Job Stress Project cohort. Am J Epidemiol. 2005;161:434-41.

35. Schupp J. The Socioeconomic Panel (SOEP). Bundesgesundheitsblatt Gesundheitsforschung Gesundheitsschutz. 2012; 55:767-74

36. Summerfield M, Freidin S, Hahn M, Ittak P, Li N, Macalalad N, et al. HILDA user manual-release 12. Melbourne, Australia: Melbourne Institute of Applied Economic and Social Research, University of Melbourne; 2013. https://melbourneinstitute. unimelb.edu.au/assets/documents/hilda-user-manual/HILDA_ User_Manual_Release_12.2.pdf.

37. Börsch-Supan A, Brugiavini A, Jürges H, Kapteyn A, Mackenbach J, SIegrist J, et al. First results from the Survey of Health, Ageing and Retirement in Europe (2004-2007). Starting the longitudinal dimension. Mannheim: Mannheim Research Institute for the Economics of Aging (MEA); 2008. 
38. Kivimaki M, Jokela M, Nyberg ST, Singh-Manoux A, Fransson EI, Alfredsson L, et al. Long working hours and risk of coronary heart disease and stroke: a systematic review and meta-analysis of published and unpublished data for 603838 individuals. Lancet. 2015;386:1739-46.

39. Virtanen M, Jokela M, Nyberg ST, Madsen IE, Lallukka T, Ahola $\mathrm{K}$, et al. Long working hours and alcohol use: systematic review and meta-analysis of published studies and unpublished individual participant data. BMJ. 2015;350:g7772.

40. WHO. Obesity: preventing and managing the global epidemic. Report of a WHO consultation. World Health Organisation Technical Report 894. Geneva: WHO; 2000.

41. Heikkila K, Nyberg ST, Fransson EI, Alfredsson L, DeBacquer D, Bjorner JB, et al. Job strain and tobacco smoking: an individualparticipant data meta-analysis of 166,130 adults in 15 European studies. PLoS One. 2012;7:e35463.

42. Kivimaki M, Singh-Manoux A, Pentti J, Sabia S, Nyberg ST, Alfredsson L, et al. Physical inactivity, cardiometabolic disease, and risk of dementia: an individual-participant meta-analysis. BMJ. 2019;365:11495.

43. Riley RD, Lambert PC, Abo-Zaid G. Meta-analysis of individual participant data: rationale, conduct, and reporting. BMJ. 2010;340:c221.
44. Rucker G, Schwarzer G, Carpenter JR, Schumacher M. Undue reliance on $\mathrm{I}(2)$ in assessing heterogeneity may mislead. BMC Med Res Methodol. 2008;8:79.

45. Yusuf S, Joseph P, Rangarajan S, Islam S, Mente A, Hystad P et al. Modifiable risk factors, cardiovascular disease, and mortality in 155,722 individuals from 21 high-income, middle-income, and lowincome countries (PURE): a prospective cohort study. Lancet. 2019. https://doi.org/10.1016/S0140-6736(19)32008-2. [Epub ahead of print].

46. Bennie JA, Chau JY, van der Ploeg HP, Stamatakis E, Do A, Bauman A. The prevalence and correlates of sitting in European adults - a comparison of 32 Eurobarometer-participating countries. Int J Behav Nutr Phys Act. 2013;10:107.

47. Connor Gorber S, Tremblay M, Moher D, Gorber B. A comparison of direct vs. self-report measures for assessing height, weight and body mass index: a systematic review. Obes Rev. 2007;8:307-26.

48. Imai T, Kuwahara K, Miyamoto T, Okazaki H, Nishihara A, Kabe I, et al. Validity and reproducibility of self-reported working hours among Japanese male employees. J Occup Health. 2016;58:340-6.

49. Kivimaki M, Kuosma E, Ferrie JE, Luukkonen R, Nyberg ST, Alfredsson L, et al. Overweight, obesity, and risk of cardiometabolic multimorbidity: pooled analysis of individual-level data for 120813 adults from 16 cohort studies from the USA and Europe. Lancet. Public Health. 2017;2:e277-e285.

\section{Affiliations}

\section{Marianna Virtanen $\mathbb{1}^{1,2} \cdot$ Markus Jokela $^{3}$ Tea Lallukka ${ }^{4,5} \cdot$ Linda Magnusson Hanson ${ }^{2} \cdot$ Jaana Pentti $^{5,6,7}$. Solja T. Nyberg ${ }^{5}$ - Lars Alfredsson ${ }^{8,9}$. G. David Batty ${ }^{10,11}$ - Annalisa Casini ${ }^{12}$. Els Clays $^{13}$. Dirk DeBacquer ${ }^{13}$. Jenni Ervasti $\mathbb{1}^{4,8}$. Eleonor Fransson ${ }^{2,8,14} \cdot$ Jaana I. Halonen ${ }^{2,4} \cdot$ Jenny Head $^{10} \cdot$ France Kittel $^{12} \cdot$ Anders Knutsson $^{15}$. Constanze Leineweber ${ }^{2}$ - Maria Nordin ${ }^{16}$ - Tuula Oksanen $^{4}$ • Olli Pietiläinen ${ }^{5}$ - Ossi Rahkonen ${ }^{5}$ Paula Salo $^{4,17}$. Archana Singh-Manoux ${ }^{10,18}$ - Sari Stenholm $\mathbb{1}^{6,7}$. Sakari B. Suominen ${ }^{6,19,20} \cdot$ Töres Theorell $^{2}$ - Jussi Vahtera ${ }^{6,7}{ }^{6,7}$ Peter Westerholm ${ }^{21} \cdot$ Hugo Westerlund ${ }^{2} \cdot$ Mika Kivimäki $^{5,10}$}

1 School of Educational Sciences and Psychology, University of Eastern Finland, Joensuu, Finland

2 Stress Research Institute, Stockholm University, Stockholm, Sweden

3 Department of Psychology and Logopedics, University of Helsinki, Helsinki, Finland

4 Finnish Institute of Occupational Health, Helsinki, Finland

5 Department of Public Health, Clinicum, University of Helsinki, Helsinki, Finland

6 Department of Public Health, University of Turku and Turku University Hospital, Turku, Finland

7 Centre for Population Health Research, University of Turku and Turku University Hospital, Turku, Finland

8 Institute of Environmental Medicine, Karolinska Institutet, Stockholm, Sweden

9 Centre for Occupational and Environmental Medicine, Stockholm County Council, Stockholm, Sweden

10 Department of Epidemiology \& Public Health, University College London, London, UK
11 School of Biological \& Population Health Sciences, Oregon State University, Corvallis, USA

12 IPSY, Université catholique de Louvain (UCLouvain), Louvainla-Neuve \& School of Public Health, Université libre de Bruxelles (ULB), Brussels, Belgium

13 Department of Public Health, Ghent University, Ghent, Belgium

14 School of Health and Welfare, Jönköping University, Jönköping, Sweden

15 Department of Health Sciences, Mid Sweden University, Sundsvall, Sweden

16 Department of Psychology, Umeå University, Umeå, Sweden

17 Department of Psychology, University of Turku, Turku, Finland

18 INSERM, U 1018 Villejuif, France

19 Folkhälsan Research Center, Helsinki, Finland

20 University of Skövde, Skövde, Sweden

21 Occupational and Environmental Medicine, Uppsala University, Uppsala, Sweden 